\title{
Over-the-scope clip system is effective for the closure of post-endoscopic submucosal dissection ulcer, especially at the greater curvature
}

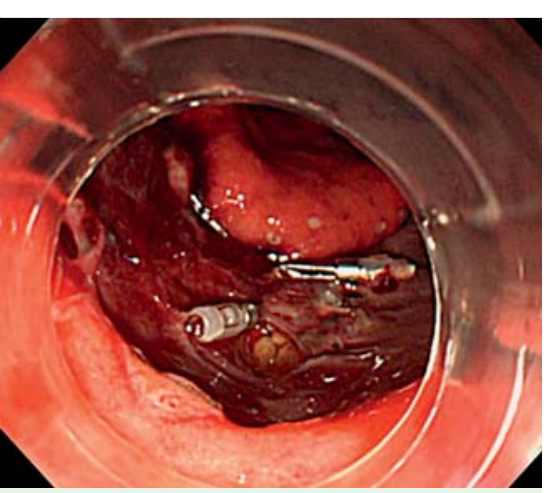

Fig. 1 Case 1. Separation and perforation of the muscle layer during endoscopic submucosal dissection with retroflexed endoscope. We tried to close the perforation site using conventional clips, but this induced further separation of the muscle layer.

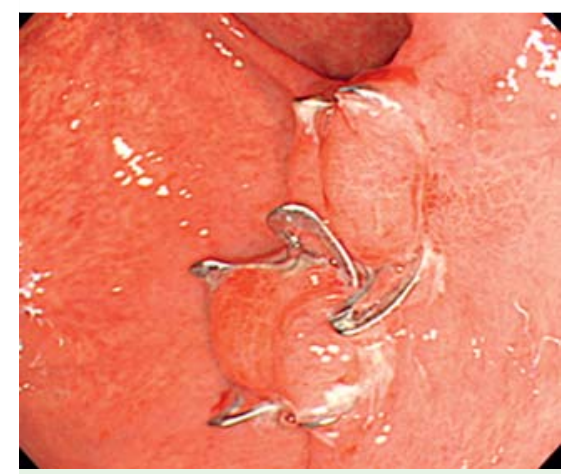

Fig. 3 Case 2. Successful closure of postendoscopic submucosal dissection ulcer using over-the-scope clips.

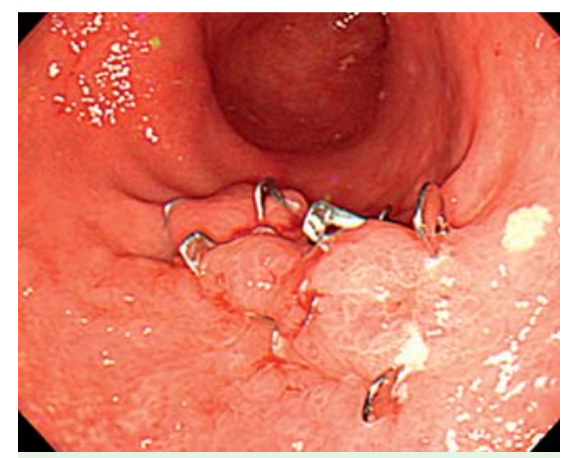

Fig. 5 Case 3. To avoid perforation we used over-the-scope clips to close the ulcer site after endoscopic submucosal dissection.

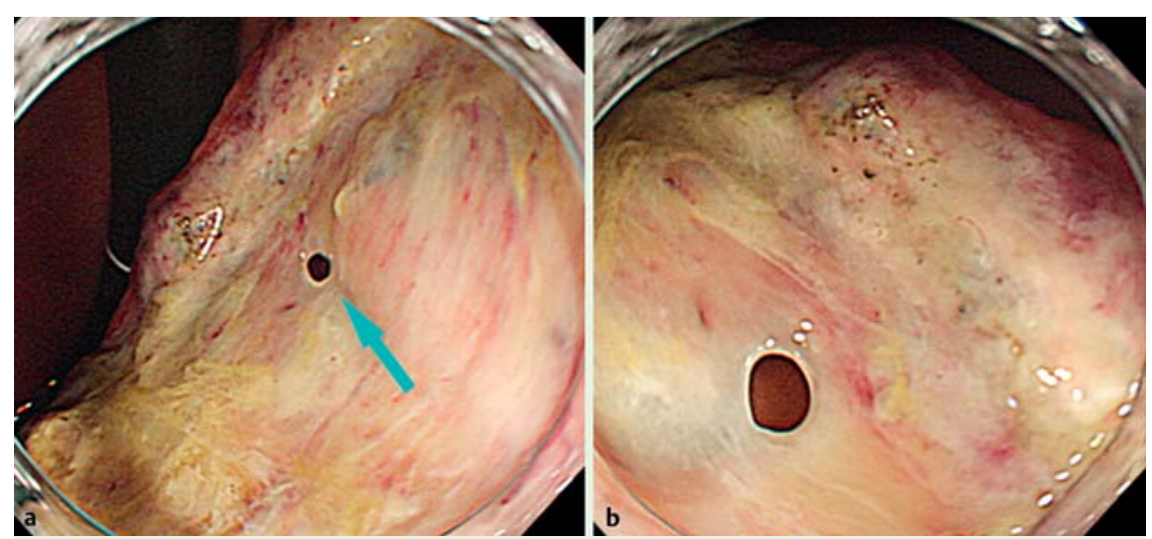

Fig.2 Case 2. a Separated muscle layer after endoscopic submucosal dissection with retroflexed endoscope. $\mathbf{b}$ Perforation site at close range.
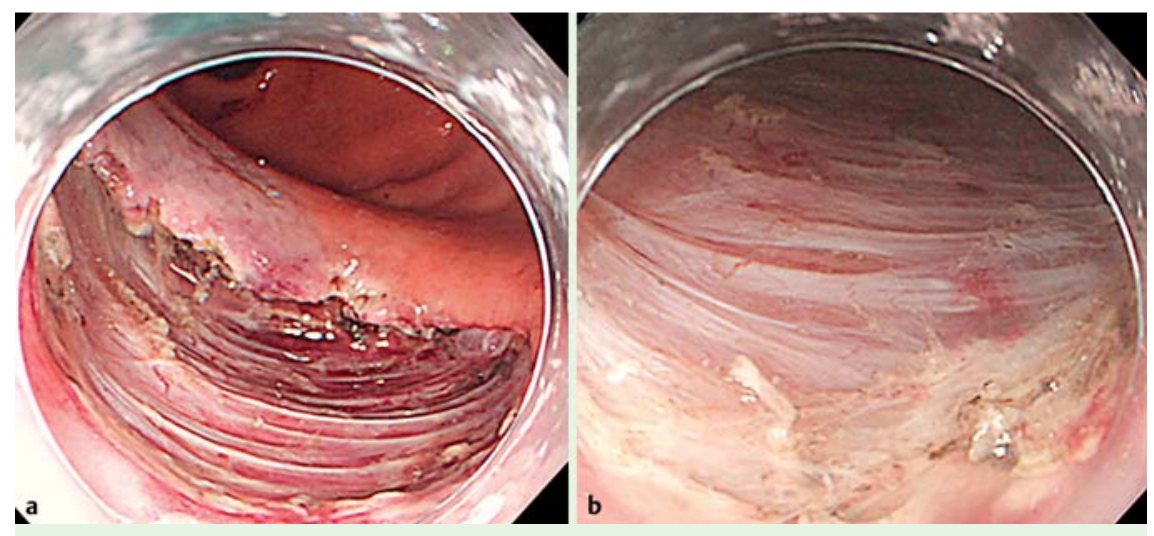

Fig. 4 Case 3. a Ulcer after endoscopic submucosal dissection. $\mathbf{b}$ Thin muscle layer which can easily be perforated.

The technique of endoscopic submucosal dissection (ESD) has been coming into widespread use and gradually becoming a standard treatment for early gastric cancers. However, perforation is a serious complication with peritonitis and the need for emergency surgery [1]. Performing ESD on lesions at the greater curvature is especially difficult, and perforation tends to occur easily [2]. We report our experience of three cases of mucosal gastric cancer at the greater curvature which were treated by ESD.

In the first case, in a 71-year-old man, perforation occurred during the ESD procedure. We tried to close the perforation site using conventional clips but were unable to do so, and in the end the patient underwent surgery ( $\bullet$ Fig. 1). The second case, in a 74-year-old man, involved iatrogenic perforation after ESD ( $\bullet$ Fig. 2 ); in this case, the ulcer perforation was successfully closed using over-the-scope clips (OTSC Clips; Ovesco Endoscopy GmbH, Tübingen, Germany) ( $\bullet$ Fig.3). In the third case ( $\bullet$ Fig.4), in an 82-year-old woman, successful closure was achieved without any complication by using overthe-scope clips to prevent perforation due to the thin muscle layer remaining after ESD ( $\bullet$ Fig.5). After 2 months, esophagogastroduodenoscopy in both cases revealed the clips remaining in place with complete closure of the post-ESD ulcer, without any complication.

There are several reasons for the vulnerability to perforation at the greater curvature during and after an ESD procedure. 


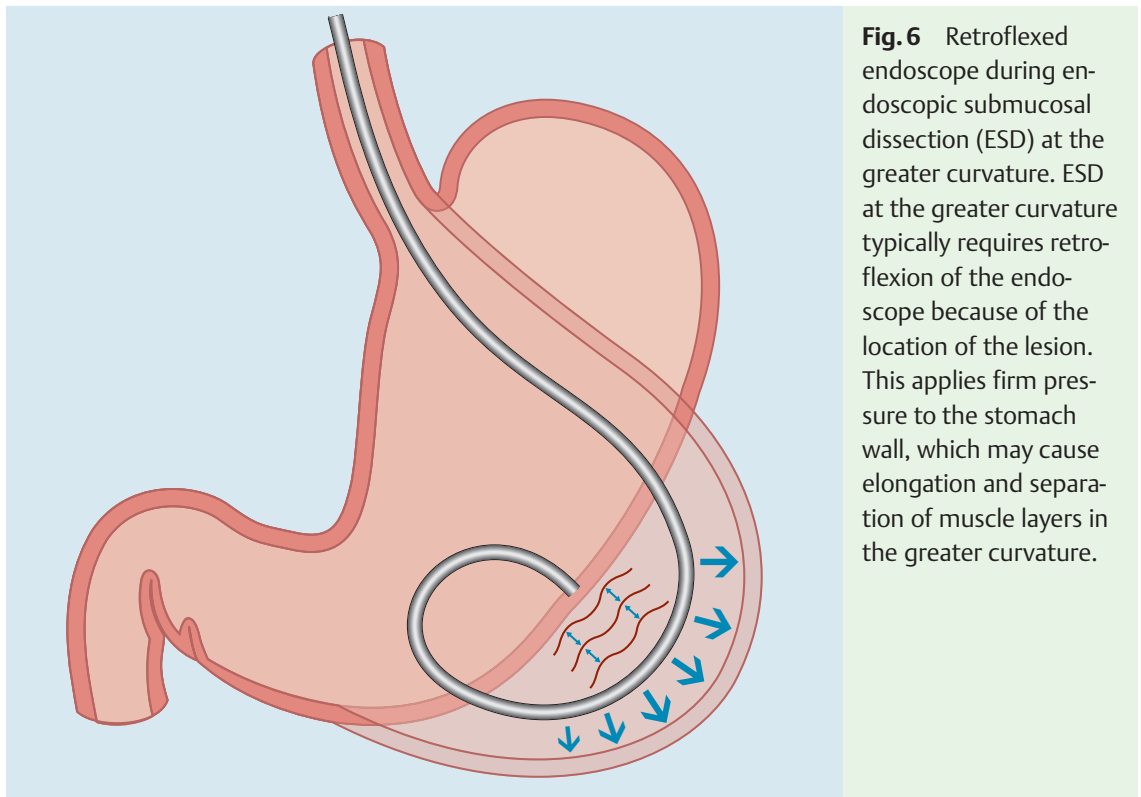

One reason is its typical anatomy [3-5]. The muscularis mucosae is thin at the greater curvature compared to other parts of the stomach, and the submucosal vascular networks are larger than in the other parts. To perform ESD at the greater curvature, typically we need to retroflex the endoscope because of the location of the lesion, thus applying firm pressure to the stomach wall, which may cause elongation and separation of muscle layers in the greater curvature ( $\bullet$ Fig.6). These technical difficulties also increase the risk of perforation.

To the best of our knowledge, our two cases are the first in which complete closure of post-ESD gastric ulcer using overthe-scope clips is reported. Comparing our three reported cases, we consider

vent perforation, especially of the thin muscle layer remaining after ESD.

\section{Endoscopy_UCTN_Code_TTT_1AO_2AC}

\section{Competing interests: None}

\section{N. Nishiyama ${ }^{1}$, H. Mori' ${ }^{1}$, K. Rafiq ${ }^{2}$, H. Kobara', S. Fujihara ${ }^{1}$, M. Kobayashi ${ }^{1}$, T. Masaki ${ }^{1}$}

${ }^{1}$ Department of Gastroenterology and Neurology, Faculty of Medicine, Kagawa University, Japan

2 Pharmacology, Faculty of Medicine,

\section{References}

1 Gotoda T, Yamamoto H, Soetikno RM. Endoscopic submucosal dissection of early gastric cancer. J Gastroenterol 2006; 41: 929-942

2 Jeon SW, Jung MK, Kim SK et al. Clinical outcomes for perforations during endoscopic submucosal dissection in patients with gastric lesions. Surg Endosc 2010; 24: 911 - 916

3 Yoo JH, Shin SJ, Lee KM et al. Risk factors for perforations associated with endoscopic submucosal dissection in gastric lesions: emphasis on perforation type. Surg Endosc 2012; 26: 2456 - 2464

4 Ohta T, Ishihara $R$, Uedo $N$ et al. Factors predicting perforation during endoscopic submucosal dissection for gastric cancer. Gastrointest Endosc 2012; 75: 1159-1165

5 Chung IK, Lee JH, Lee SH. Therapeutic outcomes in 1000 cases of endoscopic submucosal dissection for early gastric neoplasms: Korean ESD Study Group multicenter study. Gastrointest Endosc 2009; 69: 1228-1235

\section{Bibliography}

DOI http://dx.doi.org/

10.1055/s-0032-1325980

Endoscopy 2014; 46: E130-E131

(c) Georg Thieme Verlag KG

Stuttgart · New York

ISSN 0013-726X Kagawa University, Japan

\section{Corresponding author} N. Nishiyama, MD

Department of Gastroenterology and Neurology Faculty of Medicine Kagawa University 1750-1 Ikenobe, Miki, Kita Kagawa 761-0796 Japan

Fax: +81-87-8912158

n-nori@med.kagawa-u.ac.jp 